\title{
Research status and the prospect of POSTN in various tumors
}

\author{
Minireview
}

Yue YU ${ }^{1, *}$, Chang-Ming TAN ${ }^{2, *}$, Yuan-Yuan JIA ${ }^{3, *}$

${ }^{1}$ Department of Endocrinology and Metabolism, The China-Japan Union Hospital of Jilin University, Changchun, Jilin, China; ${ }^{2}$ Department of Cardiac Surgery, The Second Xiangya Hospital of Central South University, Changsha, Hunan, China; ${ }^{3}$ Health Management Medical Center, The China-Japan Union Hospital of Jilin University, Changchun, Jilin, China

${ }^{*}$ Correspondence: jiayy18@mails.jlu.edu.cn

"Contributed equally to this work.

Received February 23, 2021 / Accepted April 13, 2021

\begin{abstract}
The tumor microenvironment is considered one of the main players in tumor development and progression. The tumor microenvironment composed of a large number of extracellular matrix proteins is very complex. The continuous accumulation of extracellular matrix proteins has been shown to play a key role in tumor bioregulation, including proliferation, invasion, matrix remodeling. If these processes can be detected early, and effective interventions can be given in time, the progression of the tumor may be delayed. Therefore, there is an urgent need to explore new biomarkers and therapeutic targets. In recent years, studies have shown that periostin (POSTN) may regulate multiple biological behaviors of tumor cells. Here we review the updated progress on the role of POSTN in pathologic pathways of tumor development and progression to explore whether POSTN is a potential therapeutic target.
\end{abstract}

Key words: POSTN, extracellular matrix proteins, tumor biology, biomarker, therapeutic target

Tumor microenvironment is a complex environment for tumor cells to survive, mainly composed of a variety of different extracellular matrix (ECM) components and stromal cells. Tumor cells can alter the microenvironment and change the properties of the host tissue and vice versa, the composition of the tumor microenvironment influences the behavior of cancer cells. The extracellular matrix proteins have diverse functions, they play a central role in the homeostasis of normal tissues regulating cell proliferation and differentiation. These proteins are generally expressed at low levels in most normal tissues but they are highly expressed during inflammation, tissue repair, wound healing, and malignant transformation. Periostin (POSTN), also known as Osteoblast-specific factor 2 (OSF-2), as an extracellular matrix protein, was first discovered in a mouse osteoblast cell line in 1993 [1]. Because of its specific expression in the periodontal ligament and periosteum, it plays an important role in the formation of bones and teeth during embryonic development. The human POSTN gene is located on the long arm of chromosome 13 (13q13.3) [2], spans about 36 $\mathrm{kb}$, contains 23 exons, encodes 836 amino acids, and has a molecular weight of about $93 \mathrm{kDa}$ [3]. POSTN functions as a ligand for $\alpha v \beta 3$ and $\alpha v \beta 5$ integrins, which participates in a variety of tumor biological processes, including tumorigenesis, invasion, and metastasis. In this article, we will summarize the role of the POSTN in various tumor development and progression.

\section{Biological characteristics and functions of POSTN}

The structure and expression of POSTN. POSTN contains a typical signal sequence, 4 cysteine-rich repeat domains, and a C-terminal variable domain $[4,5]$. It is structurally homologous to $\beta$ ig- $\mathrm{H} 3$ (a $68 \mathrm{kDa}$ transforming growth factor- $\beta 1$ induced protein) and insect neural cell adhesion protein (fascilin) [6]. These proteins are essential for interacting with integrins on the cell surface. The C-terminal region of POSTN regulates the composition and interaction 
between cells and matrix by combining various extracellular matrix proteins such as type I and type $\mathrm{V}$ collagen, fibronectin, Tenascin-C, and acid mucopolysaccharide [7-9]. Its $\mathrm{N}$-terminal region contains a signal peptide (SP) for its secretion and a cysteine-rich region (EMI domain) which promotes the formation of multimers in non-reducing conditions. The N-terminal region of POSTN is highly conserved [1], which regulates the cell function by binding to integrins at the plasma membrane of the cells through its FAS domains (Figure 1).

Early researches suggested that POSTN is specifically expressed in periosteal [10] and periodontal ligament tissue [11]. Currently, it has been confirmed that POSTN exists in many tissues, such as heart, skin, tumor, and blood vessels, with the highest content in the aorta, lower digestive tract, placenta, uterus, thyroid tissue, and breast [12-17]. However, most studies have shown that POSTN expression is significantly increased in various tumors, and it is significantly related to the unfavorable prognosis. In addition, the expres- sion of POSTN will also be significantly increased in tumor pathological processes [18].

The physiological function of POSTN. The physiological expression of POSTN has important functions. POSTN is involved in maintaining the function of periodontal ligament cells and regulating the formation of periodontal ligament collagen fibers, which can promote the adhesion, proliferation, differentiation, and the periodontal-like and cementoid-like effects of periodontal ligament cells. During the formation of periodontal ligament collagen fibers, POSTN can coexist with collagen, and maintain the integrity of the periodontal ligament fiber system under mechanical stress stimulation [19]. Additionally, POSTN promotes wound healing. Ontsuka et al. [20] showed that POSTN was significantly deposited under the granulation tissue and the dermal-epidermal junction of the wound margin. Mice lacking POSTN showed delayed wound healing, which can be improved after applying exogenous POSTN. The proposed mechanism is that POSTN accelerates skin wound healing

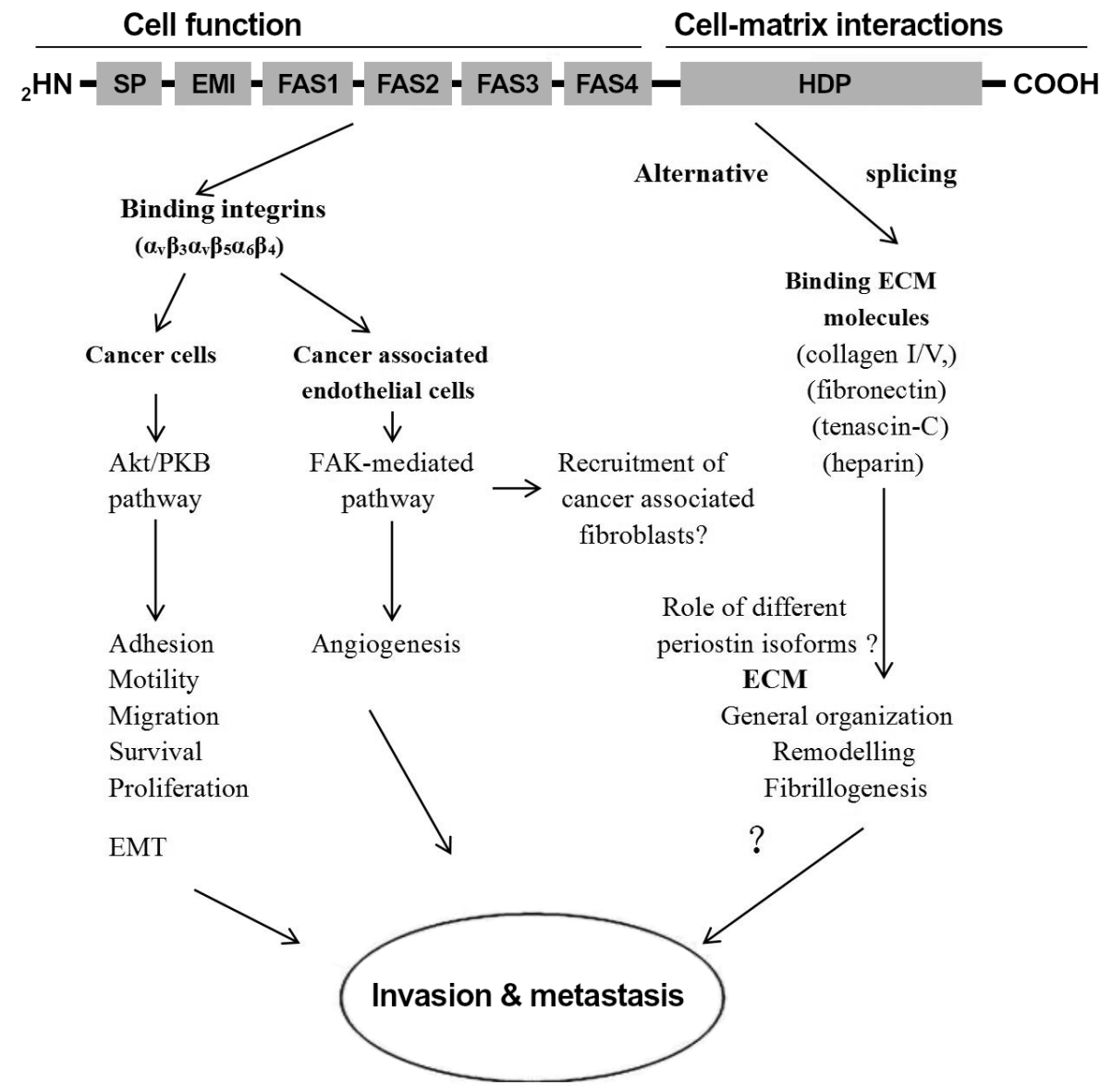

Figure 1. The role of POSTN in cancer. The N-terminal region of POSTN affects cell function and the C-terminal region affects cell-matrix interactions. POSTN binds to integrins and activates Akt/PKB and FAK-mediated signaling pathways through its FAS domains, leading to increased tumor invasion and metastasis. The C-terminal region of POSTN binds to extracellular matrix (ECM) molecules and affects the general organization of the extracellular matrix. The C-terminal of the splice isoforms of POSTN is different, and it is not clear whether they contribute differently to the formation of ECM and to the invasive and metastatic potential of the protein [82]. 
by activating fibroblasts. Besides, in cardiology, the expression of POSTN is rapidly upregulated when the myocardium is damaged or during cardiac remodeling, which helps the heart to heal and induces the proliferation of differentiated cardiomyocytes, thereby accelerating the repair process of myocardial infarction [21-29].

\section{The role of POSTN in landmark events of cancer progression}

The role of POSTN in the process of tumor development has been studied by a large number of scholars. The research has confirmed that POSTN is involved in many landmark events in the process of tumor development, including malignant proliferation, invasion and metastasis, angiogenesis (Table 1).

Promotion of cell proliferation. POSTN can induce malignant proliferation in a variety of tumor cells. Kikuchi et al. [30] showed that POSTN promotes the proliferation of gastric cancer cells by activating the ERK signaling pathway, and the growth rate of gastric cancer cells in POSTN knockout mice is lower than that of wild-type mice. Kotobuki et al. [31] have shown that the overexpression of POSTN in normal human skin fibroblasts can induce melanoma cells' proliferation by activating the MAPK signaling pathway.

Activation of cell invasion and metastasis. One of the main mechanisms involved in cell invasion and metastasis by POSTN is the epithelial-mesenchymal transition (EMT) process. EMT was firstly identified in embryos and later observed during tumor development, the process of EMT is particularly important in the development of tumors of epithelial origin. In normal epithelial cells, cells are tightly connected by apical-basal terminal polar structures, and during phenotypic transformation apical-basal terminal polar structures become less adherent, subsequently, the cell acquired the ability to invade and migrate to metastasis. The EMT process is regulated by a variety of related transcription factors, including the Snail, Twist, and Zeb families [32-37], and the deletion of epithelial E-calmodulin (E-cad) and the upregulation of waveform protein are hallmarks of EMT and key points of tumor cell malignancy. POSTN promotes the EMT process in a variety of tumor cells. Hong et al. [38] showed that POSTN induced EMT production in A549 and CL1 lung cancer cell lines, upregulated mesenchymal phenotypes (N-cadherins, wave proteins, Twist, and Snail), and downregulated E-cadherins. POSTN can also induce the EMT process of prostate cancer regulated by ERK and p38 signaling pathways. Overexpression of POSTN in PC3 and DU145 prostate cancer cell lines can promote cell proliferation, tumor cell invasion, and migration. POSTN can also upregulate the expression levels of EMT-related factors. Thereby activating the Akt-GSK-3 $\beta$ pathway [39]. Notably, POSTN can also inhibit EMT processes in specific tumors, Kim et al. [40] explored the effect of POSTN on EMT processes in bladder and prostate cancer cell lines and found that POSTN upregulated E-cad expression and inhibited bladder cancer cell invasion and metastasis, while POSTN showed the opposite effect in the prostate cancer cell, which indicated that POSTN biological functions in tumors are tissue-specific.

Many studies have demonstrated that POSTN can regulate the interactions between tumor cells and tumor microenvironment to the promotion of cell migration, and these interactions are mainly regulated by integrin family receptors. It was shown that POSTN promotes adhesion and migration of ovarian epithelial cancer cells by binding to $\alpha v \beta 3$ and $\alpha v \beta 5$ integrins, the overexpression of POSTN in ovarian cancer cells showed significantly enhanced migration and invasion

Table 1. The role of POSTN in landmark events of cancer progression.

\begin{tabular}{|c|c|c|c|}
\hline Cancer Type & Cell Line & Role of POSTN & Reference \\
\hline Gastric cancer & $\begin{array}{l}\text { OCUM-2MLN } \\
\text { OCUM-12 }\end{array}$ & Promotes proliferation & [30] \\
\hline Melanoma & $\begin{array}{l}\text { NHDF } \\
\text { SP2/O, } \\
\text { SKMEL-28 }\end{array}$ & Induces proliferation & $\begin{array}{l}{[31]} \\
{[32]}\end{array}$ \\
\hline Lung Cancer & A549, CL1 & Induces epithelial-mesenchymal transition (EMT) process & [38] \\
\hline Prostate Cancer & PC3, DU145 & $\begin{array}{l}\text { Promotes proliferation } \\
\text { Induces EMT process }\end{array}$ & [39] \\
\hline Bladder Cancer & SBT31A, T24 & Inhibits cell invasion and metastasis & {$[40]$} \\
\hline Ovarian Cancer & $\begin{array}{l}\text { HOSE, CSOC, } \\
\text { SK-OV-3 }\end{array}$ & Induces cell invasion and migration & [41] \\
\hline Esophageal Squamous Cell Carcinoma & EPC2 & Induces cell invasion and metastasis & [43] \\
\hline Oral Squamous Cell Carcinoma & Rca-B, Rca-T & Promotes cell invasion and migration & [45] \\
\hline Breast Cancer & $\begin{array}{l}\text { MCF-7, MB-231 } \\
\text { MCF-7 }\end{array}$ & $\begin{array}{l}\text { Induces metastasis } \\
\text { Promotes angiogenesis }\end{array}$ & $\begin{array}{l}{[46]} \\
{[47]}\end{array}$ \\
\hline Colorectal Cancer & CX-1NS & Induces angiogenesis & [49] \\
\hline Head and Neck Cancer & HNSCC & Promotes lymphangiogenesis & [50] \\
\hline Hepatocellular Carcinoma & SMMC7721, Нер3B & Resistance to hypoxia and arsenic trioxide & [52] \\
\hline
\end{tabular}


compared to controls [41]. Orecchia et al. [42] added antibodies against POSTN and $\alpha v \beta 3$ and $\alpha v \beta 5$ integrins to melanoma cells, and the result showed that cell proliferation was significantly inhibited, which indicated that the interaction between POSTN and integrins is essential for tumor growth. In esophageal squamous cell carcinoma, the inhibition of the EGFR signaling pathway attenuates POSTNmediated cell migration and invasion, providing further evidence for the relationship between POSTN and the EGFR pathway [43]. Cell invasion is a crucial step in the development of malignancy. During this process, metalloproteinases degrade a variety of extracellular matrix components and contribute to the ability of cells to acquire the ability to invade the surrounding matrix, and POSTN increases the activity of metalloproteinases MMP-2 (matrix metalloproteinase-2, MMP-2) and MMP-9 (metalloproteinase-9), promoting tumor cell migration and invasion [30].

Malanchi et al. [44] found that locally infiltrating tumor cells can simultaneously induce POSTN expression in distant target organs, which is important for the tumor metastasis process. In animal models, the number of liver metastases from lung cancer in POSTN knockout mice was much smaller than in wild-type controls, which indicated that POSTN is an important mediator in the process of distant tumor metastasis. In addition, POSTN secreted by tumorassociated fibroblasts (CAFs) is highly expressed in oral squamous carcinoma mesenchyme and is induced by TGF- $\beta 3$ to promote tumor cell migration and invasion [45]. Another study reported that POSTN, as an important component of the pre-metastatic microenvironment, can promote the migration of distantly metastatic melanoma cells to sites with high POSTN expression. POSTN can also preferentially metastasize to target organs in the form of exosomes. These exosomes have formed a microenvironment that is conducive to tumor cell growth before tumor cells reach the target organ, and promote tumor metastasis by shaping the tumor microenvironment. Vardaki et al. [46] found that the protein composition in exosomes derived from human metastatic breast cancer cells was significantly different from that of non-metastatic breast cancer cells. Proteomic profiling in exosomes produced by metastatic cancer cells revealed higher concentrations of adhesion proteins, including $\beta$-linked proteins, $\mathrm{N}$-calmodulin, integrin $\alpha 2$, integrin $\beta 1$, and POSTN, among others. Notably, the same phenomenon was observed in exosomes isolated from the plasma of patients with metastatic breast cancer. These studies suggest the potential of POSTN as a marker of tumor metastatic.

Induction of vascular and lymphatic vessel generation. POSTN is a potent pro-angiogenic factor, and overexpression of POSTN in breast cancer cells can promote tumor angiogenesis by binding to integrin $\alpha v \beta 3$, activating the FAK signaling pathway, and thus upregulating the VEGF receptor Flk-1/KDR in endothelial cells [47]. In esophageal cancer, Wang et al. [48] targeted the expression of POSTN and found that POSTN expression was closely related to tumor angiogenesis. Bao et al. [49] injected CX-1NS cells overexpressing POSTN into animals, and the results showed that the blood vessel density of transplanted tumors was 5 times higher than that of the control group, which suggested that POSTN secreted by tumor cells may induce tumor angiogenesis in a paracrine manner. In addition to its important role in angiogenesis, POSTN may also stimulate lymphangiogenesis. Lymphatic vessel formation and tumor cell invasion into lymph nodes are one of the most important stages of tumor progression. In in vitro model, Kudo et al. [50] found that POSTN can promote lymphatic vessel endothelial cell proliferation by activating the tyrosine kinase Src and protein kinase Akt pathways, and there was a significant correlation between POSTN expression and lymphatic vessel growth regulators and vascular endothelial growth factors. Similarly, in non-small cell lung cancer, there was a significant correlation between POSTN and lymphatic vessel density, which indicated that POSTN is an important initiator and stimulator of tumor vasculature and lymphatic vessel generation, and its potential mechanisms still need to be elucidated in the future.

Inhibition of cell apoptosis. POSTN can act as a "survival factor" to inhibit apoptosis in a variety of tumor microenvironments. In the initial stage of the PI3K/Akt signaling pathway, activated tyrosine kinase receptors bind to ligands and activate PI3K to convert phosphatidylinositol 4,5-bisphosphate (PIP2) to phosphatidylinositol 3,4,5-trisphosphate (PIP3), which recruits Akt to the cell membrane and promotes phosphorylation of serine residues. Activated Akt can inhibit apoptosis, promote tumor cell proliferation, and prolong the life span of tumor cells. It was shown that POSTN could inhibit hypoxia-induced apoptosis in tumor cells, and POSTN resisted cell death when deferoxamine was added to tumor cells to simulate a hypoxic environment. Aukkarasongsup et al. [51] showed that the rate of hypoxia-induced apoptosis was significantly higher after silencing POSTN expression using siRNA in periodontal cells. Liu et al. [52] found that in hepatocellular carcinoma cells, the expression level of POSTN was significantly increased under hypoxic conditions. Meanwhile, hypoxic environment-induced production of POSTN was able to make hepatocellular carcinoma cells resistant to the cell-killing effect of arsenic trioxide, and conversely, weak POSTN expression was able to enhance the antitumor effect of arsenic trioxide [52]. It is suggested that POSTN has an important role in inhibiting apoptosis under hypoxic conditions, and it is speculated that its mechanism of action is related to the regulation of HIF-1a, which needs to be confirmed by more studies.

Immune escape. Immunomodulation is a key factor in tumor progression and has become a new hotspot in tumor research. In glioblastoma, POSTN secreted by glioma stem cells promotes tumor proliferation and migration by recruiting tumor-associated macrophages (M2). Zhou et al. [53] found that disruption of POSTN in glioma stem cells in vivo reduced the aggregation of tumor-associated macro- 
phages and inhibited tumor growth, which suggested that the interaction between glioma stem cells and tumor-associated macrophages is regulated by POSTN regulation. In addition, POSTN promotes enrichment of myelosuppression cells in the lung during early breast cancer metastasis, a process regulated by activation of ERK, Akt, and STAT3 [54]. Studies targeting the role of POSTN in the immune escape process are still in their infancy and further evidence is needed.

\section{The expression and role of POSTN in tumors}

POSTN has been studied a lot in the field of clinical cancer, such as colorectal cancer, non-small cell lung cancer, hepatocellular carcinoma, breast cancer, etc. It has a close relationship with the deterioration and metastasis of these tumors (Table 2).

Colorectal cancer. POSTN expressed at low levels in normal colonic tissue. In the serum of CRC patients, POSTN expression levels were significantly higher than those of healthy controls and benign colorectal polyp population, and high levels of POSTN were significantly correlated with liver metastasis from colon cancer, suggesting that POSTN might be a potential biomarker for metastatic CRC [55]. Kikuchi et al. [56] found a relationship between POSTN expression and infiltrating fibroblasts in colorectal crypt fibroblasts and tumor tissue, where POSTN induced colonic crypt fibroblast proliferation, which significantly increased the number of HCT116 colon cancer cells. Studies on tumor stem cells in colon cancer have gradually become a hot topic, and CD133, a transmembrane glycoprotein with a molecular weight of $120 \mathrm{kDa}$, was initially thought to be a marker of hematopoietic stem cells and also highly expressed in a variety of solid tumors [57]. Wu et al. [57] found that in CD133-positive colon cancer HCT116 cells, the expression level of POSTN was significantly higher than that of CD133-negative cells, and the CD133-positive cell subpopulation had a cloneforming ability. However, the regulatory relationship between CD133 and POSTN has not been elucidated, and the specific mechanism needs to be further explored.
POSTN can be involved in the proliferative metabolism of colon cancer cells through induction of the Akt/PKB pathway, while inhibition of the Akt/PKB pathway activates caspase-9 to promote apoptosis [58].

In conclusion, POSTN is important in the proliferation and metastasis of colon cancer cells, and the expression level of POSTN correlates with the prognosis of colon cancer patients and may be a biological marker for assessing the prognosis of colon cancer patients.

Non-small cell lung cancer, NSCLC. In normal lung tissue, POSTN was weakly expressed in the bronchial basement membrane and was not expressed in alveolar macrophages. POSTN is commonly overexpressed and promotes angiogenesis and lymphangiogenesis in NSCLC [59, 60]. In NSCLC, Sasaki et al. [61] observed POSTN expression in the mesenchymal tissue region of the tumor stroma while no POSTN expression was seen in tumor endothelial cells, which suggested that POSTN may function mainly in the tumor microenvironment. In another similar study, Zhang et al. [62] found that serum POSTN levels were significantly higher in patients with NSCLC than in healthy controls, and serum POSTN levels were significantly associated with bone metastases and lymph node infiltration, and the differential expression of POSTN before and after chemotherapy was significantly associated with prognosis, which suggested that POSTN could be used as a biomarker to predict the efficacy of chemotherapy in patients with advanced NSCLC. Che et al. [63] studied POSTN levels in the serum of patients with lung cancer with bone metastases and lung cancer without bone metastases and found that POSTN concentrations were higher in patients with lung cancer with bone metastases than patients with lung cancer without bone metastases. In another study, although serum POSTN levels were significantly higher in lung cancer patients, no correlation was found between serum POSTN levels and clinicopathological parameters [38].

Taken together, high expression of POSTN may be an independent prognostic marker for NSCLC and play an important role in NSCLC progression.

Table 2. The role of POSTN in cancers: an overview of POSTN function and correlated signaling pathway.

\begin{tabular}{|c|c|c|c|}
\hline Cancer Type & Correlated Signaling Pathway & POSTN Function & Reference \\
\hline \multirow[t]{3}{*}{ Colorectal Cancer } & avb3 integrin via $\mathrm{Akt} / \mathrm{PKB}$ & $\begin{array}{l}\text { Promotes cell survival, proliferation, and resis- } \\
\text { tance to stress conditions } \\
\text { Induces tumor angiogenesis }\end{array}$ & [58] \\
\hline & Via VEGFR & $\begin{array}{l}\text { Promotes cell proliferation, migration, and an- } \\
\text { chorage independent growth of fibroblasts }\end{array}$ & [49] \\
\hline & PI3K/Akt AND Wnt/ $\beta$-catenin & & [56] \\
\hline $\begin{array}{l}\text { Non-small Cell Lung Cancer, } \\
\text { NSCLC }\end{array}$ & - & $\begin{array}{l}\text { Increases tumor proliferation } \\
\text { Promotes lymph node and lung metastases }\end{array}$ & $\begin{array}{l}{[59]} \\
{[60]}\end{array}$ \\
\hline Hepatocellular Carcinoma & TGF $\beta 1-$ Smad & Induce tumor angiogenesis & [72] \\
\hline Breast Cancer & $\alpha v \beta 3$ integrin via FAK signaling. & Promotes tumor angiogenesis and cell survival & [47] \\
\hline Bladder Cancer & PDK1/Akt/mTOR signaling & Suppresses invasiveness of bladder cancer & [78] \\
\hline
\end{tabular}


Hepatocellular carcinoma. POSTN was expressed at high levels in both liver tumor epithelial and basal cells. Riener et al. [64] found that the expression level of POSTN in tumor epithelial cells was negatively correlated with overall survival and positively correlated with tumor stage. In another study, POSTN was significantly correlated with tumor size, tumor stage, tumor microvessel density, and VEGF expression levels, and POSTN was an independent risk factor for predicting overall survival and progression-free survival [65]. In a recent study, Jang et al. [66] found that high levels of POSTN expression in hepatocellular carcinoma tissues were associated with microvascular invasion and that patients with advanced disease overexpressing POSTN had significantly shorter survival and poor prognosis. High serum POSTN expression was negatively correlated with overall survival and progression-free survival, and POSTN was an independent risk factor for patient survival in a multifactorial analysis [67]. Fujimoto et al. [68] analyzed the serum expression levels of POSTN in patients with intrahepatic cholangiocarcinoma and found that POSTN expression levels were much higher than those in patients with cirrhosis and hepatocellular carcinoma, suggesting that serum POSTN levels may be used as a biomarker to differentiate intrahepatic cholangiocarcinoma from other liver malignancies. Similar results were also observed in a recent study, where serum POSTN levels were much higher in patients with cholangiocarcinoma than in healthy controls, patients with benign liver disease, and even patients with breast cancer, suggesting that serum POSTN levels may be an independent prognostic marker for hepatocellular carcinoma and assist in the identification of intrahepatic cholangiocarcinoma [69].

The pathological mechanism of POSTN-induced hepatocellular carcinoma is less studied, Engelmann et al. [70] found that abnormal hepatic stellate cells (HSC) and tumor cells can transmit information via paracrine secretion. Activated HSC secrete POSTN, which in turn induces tumor proliferation, invasion, and migration. Studies have confirmed that hypoxia can lead to drug resistance in hepatocellular carcinoma cells [71]. Another study investigated the role of POSTN and sulfatase 2 (SULF2) on angiogenesis in hepatocellular carcinoma, the result showed POSTN significantly inhibited angiogenesis and tumor growth [72]. Available research evidence suggests that POSTN has an important role in the proliferation, angiogenesis, and development of tumor cell resistance in primary hepatocellular carcinoma.

Breast cancer. POSTN is also involved in the proliferative metabolism of breast cancer cells. POSTN is mainly expressed in the cytoplasm of breast cancer cells and in the tumor mesenchyme. Puglisi et al. [73] found significantly higher expression of POSTN in breast cancer tissues by comparing with normal tissues. The mRNA levels of POSTN were found to be 20 -fold higher in breast cancer tissues than in normal tissues by gene array analysis, while western blot and immunohistochemistry results similarly supported this finding. High levels of POSTN expression were significantly associated with poor disease prognosis, including progression-free survival and overall survival [74]. The expression of POSTN in the cytoplasm correlated with tumor size, VEGF-A, progesterone, and VEFG-R1, but not with tumor stage, estrogen receptor, or $\mathrm{Ki}-67$ expression. This finding suggested an important role of POSTN for angiogenesis. Recent studies have shown that POSTN is highly expressed in breast cancer stem cells and is more likely to be tumorigenic in mice. Furthermore, multifactorial analysis suggests that high expression of POSTN may be an independent prognostic factor for breast cancer.

Bladder cancer. Bladder cancer is the most common malignant tumor of the urinary system, and its incidence is the first among genitourinary tumors in China. The number of diagnosed bladder cancer in the USA in 2017 was about 80,000; accounting for $5 \%$ of all cancer diagnoses [75].

Unlike other cancers, POSTN expression is downregulated in bladder cancer. Immunohistochemical analysis showed that POSTN was expressed in brownish color in the basal cells of normal bladder tissues, while POSTN expression was not detected in bladder cancer tissues. POSTN expression was detectable in all normal bladder tissues, whereas it was detected in only $33 \%$ of stage III bladder cancer tissues [76]. Normal bladder tissues express the typical POSTN heterodimer, as well as other mRNA types generated by variable splicing. In contrast in bladder cancer tissues, typical POSTN isoforms could not be detected or only a small fraction of variable spliced isoforms was present. Interestingly, the variable spliced isoforms had an inhibitory effect on tumor cell growth. These findings suggest that the absence of the typical POSTN isoform is closely associated with the development of bladder cancer.

However, several studies have shown that POSTN can promote the development of bladder cancer. Invasive bladder cancer is highly malignant and extremely lethal, and in this type of bladder cancer, high levels of POSTN expression are associated with a poor prognosis. Tumor cells can promote cancer development by secreting exosomes, and exosomes isolated from the urine of bladder cancer patients contain high levels of POSTN mRNA, suggesting that POSTN could be a potential urinary marker for invasive bladder cancer [77]. Kim et al. [78] revealed that the invasive process of invasive bladder cancer is regulated by the PDK1/Akt/ mTOR signaling pathway, and POSTN may serve as a potential therapeutic target to inhibit the invasiveness of invasive bladder cancer. This finding suggests an important role of POSTN for bladder cancer.

\section{POSTN could be a potential therapeutic target}

Because of its important role in key events of tumor progression, POSTN may be a potential new therapeutic target. Various clinical models have shown that inhibition of POSTN expression can slow down the rate of tumor proliferation. Lee et al. [79] used benzyl-d(U)TP-modified 
DNA oligonucleotide aptamers (PDNAs) to inhibit POSTN expression in a mouse model of breast cancer to effectively prevented tumor growth and cell migration. In addition, Kyutoku et al. [80] used POSTN antibodies against POSTN exon 17 to treat mice with lung metastatic carcinoma and significantly inhibited the proliferation of tumor cells in situ and metastatic foci in the lung. Zhu et al. [81] used antiPOSTN monoclonal antibodies to inhibit POSTN expression in a mouse ovarian cancer model and significantly reduced the number of metastatic foci compared with the control group. Currently, more and more studies have demonstrated the important role of POSTN in cancer development, and POSTN is involved in several landmark events of tumor progression, playing an important role in tumor diagnosis, treatment, and prognosis.

\section{Conclusion and perspective}

POSTN is highly expressed in a variety of tumors, and higher expression levels of POSTN are significantly associated with a poor prognosis. In future studies, large cohort studies and high-quality controlled trials are needed to investigate the changes in POSTN expression levels in tumors with different treatments as a way to determine whether POSTN can be an ideal biomarker. Many studies have addressed the correlation between POSTN expression levels in serum of tumor patients and prognosis, but the conclusions have not been uniform. In addition, the exact mechanism by which POSTN induces drug resistance in tumor cells still needs to be investigated in depth. POSTN secreted by the tumor mesenchyme facilitates the formation of a microenvironment for tumor metastasis, and current studies suggested that POSTN can reach target organs in the form of exosomes, so the block of exosomal transport may become a new therapeutic direction. In conclusion, POSTN as a multifunctional protein is involved in regulating the development of various tumors, and its mechanism of action will be improved as researchers further investigate POSTN in tumors. It is expected that POSTN will become a target for tumor therapy in the future.

\section{References}

[1] TAKEHITA S, KIKUNO R, TEZUKA K, AMMAN E. Osteoblast-specific factor 2: cloning of a putative bone adhesion protein with homology with the insect protein fasciclin I. Biochem J 1993; 294: 271-278. https://doi.org/10.1042/ bj2940271

[2] LITVIN J, SELIM AH, MONTGOMERY MO, LEHMANN $\mathrm{K}$, RICO MC et al. Expression and function of periostin-isoforms in bone. J Cell Biochem 2004; 92: 1044-1061. https:// doi.org/10.1002/jcb.20115

[3] NUZZOP V, BUZZATTI G, RICCI F, RUBAGOTTI A, ARGELLATI F et al. Periostin: a novel prognostic and therapeutic target for genitourinary cancer? Clin Genitourin Cancer 2014; 12: 301-311. https://doi.org/10.1016/j.clgc.2014.02.005
[4] YANG T, DENG Z, PAN Z, QIAN Y, YAO W et al. Prognostic value of periostin in multiple solid cancers: A systematic review with meta-analysis. J Cell Physiol 2020; 235: 28002808. https://doi.org/10.1002/jcp.29184

[5] KUDO A. Introductory review: periostin-gene and protein structure. Cell Mol Life Sci 2017; 74: 4259-4268. https://doi. org/10.1007/s00018-017-2643-5

[6] IZUHARA K, NUNOMURA S, NANRI Y, ONO J, TAKAI $\mathrm{M}$ et al. Periostin: An emerging biomarker for allergic diseases. Allergy 2019; 74: 2116-2128. https://doi.org/10.1111/ all.13814

[7] LIU Y, HUANG Z, CUI D, OUYANG G. The Multiaspect Functions of Periostin in Tumor Progression. Adv Exp Med Biol 2019; 1132: 125-136. https://doi.org/10.1007/978-98113-6657-4_13

[8] KII I. Periostin Functions as a Scaffold for Assembly of Extracellular Proteins. Adv Exp Med Biol 2019; 1132: 23-32. https://doi.org/10.1007/978-981-13-6657-4_3

[9] KUDO A. The Structure of the Periostin Gene, Its Transcriptional Control and Alternative Splicing, and Protein Expression. Adv Exp Med Biol 2019; 1132: 7-20. https://doi. org/10.1007/978-981-13-6657-4_2

[10] HORIUCHI K, AMIZUKA N, TAKESHITA S, TAKAMATSU H, KATSUURA M et al. Identification and characterization of a novel protein, periostin, with restricted expression to periosteum and periodontal Ligament and increased expression by transforming growth factor beta. J Bone Miner Res 1999; 14: 1239-1249. https://doi.org/10.1359/ jbmr.1999.14.7.1239

[11] LINDNER V, WANG Q, CNLEY BA, FRIESEL RE et al. Vascular injury induces expression of periostin: implications for vascular cell differentiation and migration. Arterioscler Thromb Vasc Biol 2005; 25: 77-83. https://doi. org/10.1161/01.ATV.0000149141.81230.c6

[12] LITVIN J, SELIM AH, MONTGOMERY MO, LEHMANN $\mathrm{K}, \mathrm{RICO} \mathrm{MC}$ et al. Expression and function of Periostin-isoforms in bone. J Cell Biochem 2004; 92: 1044-1061. https:// doi.org/10.1002/jcb.20115

[13] IDOLAZZI L, RIDOLO E, FASSIO A, GATTI D, MONTAGNI M et al. Periostin: The bone and beyond. Eur J Intern Med 2017; 38: 12-16. https://doi.org/10.1016/j.ejim.2016.11.015

[14] NORRIS RA, MORENO-RODRIGUEZ RA, SUGI Y, HOFFMAN S, AMOS J et al. Periostin regulates atrioventricular valve maturation. Dev Biol 2008; 316(2): 200-213. https://doi.org/10.1016/j.ydbio.2008.01.003

[15] LI P, OPARIL S, FENG W, CHEN YF. Hypoxia-responsive growth factors upregulate periostin madosteo-pontin expression via distinct signaling pathways in rat pulmonary arterial smooth muscle cells. J Appl Physiol 2004; 97: 15501558. https://doi.org/10.1152/japplphysiol.01311.2003

[16] BONNET N, GARNERO P, FERRARI S. Periostin action in bone. Mol Cell Endocrinol 2016; 432: 75-82. https://doi. org/10.1016/j.mce.2015.12.014

[17] JACKSON-BOETERS L, WEN W, HAMILTON DW. Periostin localizes to cells in normal skin, but is associated with the extracellular matrix during wound repair. J Cell Commun Signal 2009; 3: 125-133. https://doi.org/10.1007/s12079009-0057-3 
[18] GONZÁLES-GONZÁLES L, ALONSO J. Periostin: a matricellular protein with multiple functions in cancer development and progression. Front Oncol 2018; 8: 225. https://doi. org/10.3389/fonc.2018.00225

[19] HAN T, MignatTi P, ABRAMSON SB, ATTUR M. Periostin interaction with discoidin domain receptor-1 (DDR1) promotes cartilage degeneration. PLoS One 2020; 15: e0231501. https://doi.org/10.1371/journal.pone.0231501

[20] ONTSUKA K, KOTOBUKI Y, SHIRAISHI H, SERADA S, OHTA $S$ et al. Periostin, a matricellular protein, accelerates cutaneous wound repair by activating dermal fibroblasts. Experimental Dermatology 2012; 21: 331-336. https://doi. org/10.1111/j.1600-0625.2012.01454.x

[21] MARKWALD RR, NORRIS RA, MORENO-RODRIGUEZ $\mathrm{R}$, LEVINE RA. Developmental basis of adult cardiovascular diseases: valvular heart diseases. Ann N Y Acad Sci 2010; 1188: 177-183. https://doi.org/10.1111/j.17496632.2009.05098.x

[22] SOROCOS K, KOSTOULIAS X, CULLEN-MCEWEN L, HART AH, BERTRAM JF et al. Expression patterns and roles of Periostin during kidney and ureter development. J Urol 2011; 186: 1537-1544. https://doi.org/10.1016/j. juro.2011.05.042

[23] HAKUNO D, KIMURA N, YOSHIOKA M, MUKAI M, KIMURA T et al. Periostin advances atherosclerotic and rheumatic cardiac valve degeneration by inducing angiogenesis and MMP production in humans and rodents. J Clin Invest 2010; 120: 2292-2306. https://doi.org/10.1172/JCI40973

[24] WEI C, MOLLER CC, ALTINTAS MM, LI J, SCHWARZ $\mathrm{K}$ et al. Modification of kidney barrier function by the urokinase receptor. Nat Med 2008; 14: 55-63. https://doi. org/10.1038/nm1696

[25] KANG YS, LI Y, DAI C, Kiss LP, Wu C et al. Inhibition of integrin - linked kinase blocks podocyte epithelial-mesenchymal transition and ameliorates proteinuria. Kidney Int 2010; 78: 363-373. https://doi.org/10.1038/ki.2010.137

[26] WALLACE DP, QUANTE MT, REIF GA, NIVENS E, AHMED $\mathrm{F}$ et al. Periostin induces proliferation of human autosomal dominant polycystic kidney cells through alphaVintegrin receptor. Am J Physiol Renal Physiol 2008; 295: F1463-F1471. https://doi.org/10.1152/ajprenal.90266.2008

[27] INAI K, NORRIS RA, HOFFMAN S, MARKWALD RR, SUGI Y. BMP-2 induces cell migration and Periostin expression during atrioventricular valvulogenesis. Dev Biol 2008; 315: 383-396. https://doi.org/10.1016/j.ydbio.2007.12.028

[28] NORRIS RA, MORENO-RODRIGUEZ R, HOFFMAN S, MARKWALD RR. The many facets of the matricelluar protein Periostin during cardiac development, remodeling, and pathophysiology. J Cell Commun Signal 2009; 3: 275-286. https://doi.org/10.1007/s12079-009-0063-5

[29] OSHIMA A, TANABE H, YAN T, LOWE GN, GLACKIN $\mathrm{CA}$ et al. A novel mechanism for the regulation of osteoblast differentiation: transcription of Periostin, a member of the fasciclin I family, is regulated by the bHLH transcription factor, twist. J Cell Biochem 2002; 86: 792-804. https://doi. org/10.1002/jcb.10272
[30] KIKUCHI Y, KUNITA A, IWATA C, KOMURA D, NISHIYAMA $\mathrm{T}$ et al. The niche component periostin is produced by cancer-associated fibroblasts, supporting growth of gastric cancer through ERK activation. Am J Pathol 2014; 184: 859-70. https://doi.org/10.1016/j.ajpath.2013.11.012

[31] KOTOBUKI Y, YANG L et al. Periostin accelerates human malignant melanoma progression by modifying the melanoma microenvironment. Pigment Cell Melanoma Res 2014; 27: 630-639. https://doi.org/10.1111/pcmr.12245

[32] WANG Y, SHI J, CHAI K, YING X, ZHOU BP. The Role of Snail in EMT and Tumorigenesis. Curr Cancer Drug Targets 2013; 13: 963-972. https://doi.org/10.2174/15680096113136 660102

[33] ZHENG X, CARSTENS JL, KIM J, SCHEIBLE M, KAYE J et al. Epithelial-to-mesenchymal transition is dispensable for metastasis but induces chemoresistance in pancreatic cancer. Nature 2015; 527: 525-530. https://doi.org/10.1038/ nature 16064

[34] NOROZ F, AHMADZADEH A, SHAHJAHANI M, SHAHRABI S, SAKI N. Twist as a new prognostic marker in hematological malignancies. Clin Transl Oncol 2016; 18: 113-124. https://doi.org/10.1007/s12094-015-1357-0

[35] NUTI SV, MOR G, LI P, YIN G. Twist and ovarian cancer stem cells: implications for chemoresistance and metastasis. Oncotarget 2014; 5: 7260-7271. https://doi.org/10.18632/ oncotarget. 2428

[36] YANG J, MANI SA, WEINBERG RA. Exploring a new twist on tumor metastasis. Cancer Res 2006; 66: 4549-4552. https://doi.org/10.1158/0008-5472.CAN-05-3850

[37] DAVE N, GUAITA-ESTERUELAS S, GUTARRA S, FRIAS A, BELTRAN $M$ et al. Functional cooperation between snaill and twist in the regulation of ZEB1 expression during epithelial to mesenchymal transition. J Biol Chem 2011; 286: 12024-12032. https://doi.org/10.1074/jbc.M110.168625

[38] HONG L, SUN H, LV X, YANG D, ZHANG J et al. Expression of periostin in the serum of NSCLC and its function on proliferation and migration of human lung adenocarcinoma cell line (A549) in vitro. Mol Biol Rep 2010; 37: 2285-2293. https://doi.org/10.1007/s11033-009-9721-1

[39] HU Q, TONG S, ZHAO X, DING W, GOU Y et al. Periostin mediates TGF-beta-induced epithelial mesenchymal transition in prostate cancer cells. Cell Physiol Biochem 2015; 36: 799-809. https://doi.org/10.1159/000430139

[40] KIM CJ, SAKAMOTO K, TAMBE Y, INOUE H. Opposite regulation of epithelial-to-mesenchymal transition and cell invasiveness by periostin between prostate and bladder cancer cells. Int J Oncol 2011; 38: 1759-1766. https://doi. org/10.3892/ijo.2011.997

[41] GILLAN L, MATEI D, FISHMAN DA, GERBIN CS, KARLAN BY et al. Periostin secreted by epithelial ovarian carcinoma is a ligand for alpha(V)beta(3) and alpha(V)beta(5) integrins and promotes cell motility. Cancer Res 2002; 62: 5358-5364.

[42] OERCCHIA P, CONTE R, BALZA E, CASTELLANI P, BORSI $L$ et al. Identification of a novel cell binding site of periostin involved in tumour growth. Eur J Cancer 2011; 47: 2221-2229. https://doi.org/10.1016/j.ejca.2011.04.026 
[43] MICHAYLIRA CZ, WONG GS, MILLER CG, GUTIERREZ CM, NAKAGAWA $\mathrm{H}$ et al. Periostin a cell adhesion molecule, facilitates invasion in the tumor microenvironment and annotates a novel tumor-invasive signature in esophageal cancer. Cancer Res 2010; 70: 5281-5292. https://doi. org/10.1158/0008-5472.CAN-10-0704

[44] MALANCHI I, SANTAMARIA-MARTINEZ A, SUSANTO E, PENG H, LEHR HA et al. Interactions between cancer stem cells and their niche govern metastatic colonization. Nature 2011; 481: 85-89. https://doi.org/10.1038/nature10694

[45] QIN X, YAN M, ZHANG J, WANG X, SHEN Z et al. TGFß3mediated induction of Periostin facilitates head and neck cancer growth and is associated with metastasis. Sci Rep 2016; 6: 20587. https://doi.org/10.1038/srep20587

[46] VARDAKI I, CEDER S, RUTISHAUSER D, BALTATZIS G, FOUKAKIS T et al. Periostin is identified as a putative metastatic marker in breast cancer-derived exosomes. Oncotarget 2016; 7: 74966-74978. https://doi.org/10.18632/oncotarget. 11663

[47] SHAO R, BAO S, BAI X, BLANCHETTE C, ANDERSON $\mathrm{RM}$ et al. Acquired expression of periostin by human breast cancers promotes tumor angiogenesis through up-regulation of vascular endothelial growth factor receptor 2 expression. Mol Cell Biol 2004; 24: 3992-4003. https://doi.org/10.1128/ MCB.24.9.3992-4003.2004

[48] WANG W, SUN QK, HE YF, MA DC, XIE MR et al. Overexpression of periostin is significantly correlated to the tumor angiogenesis and poor prognosis in patients with esophageal squamous cell carcinoma. Int J Clin Exp Pathol 2014; 7: 593601.

[49] BAO S, OUYANG G, BAI X, HUANG Z, MA C et al. Periostin potently promotes metastatic growth of colon cancer by augmenting cell survival via the Akt/PKB pathway. Cancer Cell 2004; 5: 329-339. https://doi.org/10.1016/s15356108(04)00081-9

[50] KUDO Y, IIZUKA S, YOSHIDA M, NGUYEN PT, SIRIWARDENA SBSM et al. Periostin directly and indirectly promotes tumor lymphangiogenesis of head and neck cancer. PLoS One 2012; 7: e44488. https://doi.org/10.1371/journal.pone.0044488

[51] AUKKARASONGSUP P, HARUYAMA N, MATSUMOTO T, SHIGA M, MORIYAMA K. Periostin inhibits hypoxiainduced apoptosis in human periodontal ligament cells via TGF- $\beta$ signaling. Biochem Biophys Res Commun 2013; 441: 126-132. https://doi.org/10.1016/j.bbrc.2013.10.027

[52] LIU Y, GAO F, SONG W. Periostin contributes to arsenic trioxide resistance in hepatocellular carcinoma cells under hypoxia. Biomed Pharmacother 2017; 88: 342-348. https:// doi.org/10.1016/j.biopha.2017.01.052

[53] ZHOU W, KE SQ, HUANG Z, FLAVAHAN W, FANG X et al. Periostin secreted by glioblastoma stem cells recruits M2 tumor-associated macrophages and promotes malignant growth. Nat Cell Biol 2015; 17: 170-182. https://doi. org/10.1038/ncb3090
[54] WANG Z, XIONG S, MAO Y, CHEN M, MA X et al. Periostin promotes immunosuppressive premetastatic niche formation to facilitate breast tumour metastasis. J Pathol 2016; 239: 484-495. https://doi.org/10.1002/path.4747

[55] BEN QW, ZHAO Z, GE SF, ZHOU J, YUAN F et al. Circulating levels of periostin may help identify patients with more aggressive colorectal cancer. Int J Oncol 2009; 34: 821-828. https://doi.org/10.3892/ijo_00000208

[56] KIKUCHI Y, KASHIMA TG, NISHIYAMA T, SHIMAZU $\mathrm{K}$, MORISHITA $\mathrm{Y}$ et al. Periostin is expressed in pericryptal fibroblasts and cancer-associated fibroblasts in the colon. J Histochem Cytochem 2008; 56: 753-764. https://doi. org/10.1369/jhc.2008.951061

[57] WU G, WANG X, ZHANG X. Clinical implications of periostin in the liver metastasis of colorectal cancer. Cancer Biother Radiopharm 2013; 28: 298-302. https://doi.org/10.1089/ cbr.2012.1374

[58] XU X, CHANG W, YUAN J, HAN X, TAN X et al. Periostin expression in intra-tumoral stromal cells is prognostic and predictive for colorectal carcinoma via creating a cancersupportive niche. Oncotarget 2016; 7: 798-813. https://doi. org/10.18632/oncotarget.5985

[59] OKAZAKI T, TAMAI K, SHIBUYA R, NAKAMURA M, MOCHIZUKI M ET al. Periostin is a negative prognostic factor and promotes cancer cell proliferation in non-small cell lung cancer. Oncotarget 2018; 9: 31187-31199. https:// doi.org/10.18632/oncotarget.25435

[60] TAKANAMI I, ABIKO T, KOIZUMI S. Expression of periostin in patients with nonesmall-cell lung cancer: correlation with angiogenesis and lymphangiogenesis. Int J Biol Markers 2008; 23: 182-186. https://doi.org/10.5301/jbm.2008.1999

[61] SASAK H, DAI M, AUCLAIR D, FUKAI I, KIRIYAMA $M$ et al. Serum level of the periostin, a homologue of an insect cell adhesion molecule, as a prognostic marker in nonsmall cell lung carcinomas. Cancer 2001, 92: 843-848. https://doi.org/10.1002/1097-0142(20010815)92:4<843::aidcncr 1391>3.0.co;2-p

[62] ZHANG Y, YUAN D, YAO Y, SUN W, SHI Y et al. Predictive and prognostic value of serum periostin in advanced non-small cell lung cancer patients receiving chemotherapy. Tumour Biol 2017; 39: 1010428317698367. https://doi. org/10.1177/1010428317698367

[63] CHE J, SHEN W Z, DENG Y, DAI YH, LIAO YD et al. Effects of lentivirus-mediated silencing of Periostin on tumor microenvironment and bone metastasis via the integrinsignaling pathway in lung cancer. Life Sci 2017; 182: 10-21. https://doi.org/10.1016/j.lfs.2017.05.030

[64] RIENER MO, FRITZSCHE FR, SOLL C, PESTALOZZI BC, PROBST-HENSCH N et al. Expression of the extracellular matrix protein periostin in liver tumours and bile duct carcinomas. Histopathology 2010; 56: 600-606. https://doi. org/10.1111/j.1365-2559.2010.03527.x

[65] LV Y, WANG W, JIA WD, SUN QK, LI JS et al. High-level expression of periostin is closely related to metastatic potential and poor prognosis of hepatocellular carcinoma. Med Oncol 2013; 30: 385. https://doi.org/10.1007/s12032-0120385-7 
[66] JANG SY, PARK SY, LEE HW, CHOI YK, PARK KG et al. The combination of Periostin overexpression and microvascular invasion is related to a poor prognosis for hepatocellular carcinoma. Gut Liver 2016; 10: 948-954. https://doi. org/10.5009/gnl15481

[67] LV Y, WANG W, JIA WD, SUN QK, HUANG M et al. High preoparative levels of serum periostin are associated with poor prognosis in patients with hepatocellular carcinoma after hepatectomy. Eur J Surg Oncol 2013; 39: 1129-1135. https://doi.org/10.1016/j.ejso.2013.06.023

[68] FUJIMOTO K, KAWAGUCHI T, NAKASHIMA O, ONO J, OHTA $S$ et al. Periostin, a matrix protein, has potential as a novel serodiagnostic marker for cholangiocarcinoma. Oncol Rep 2011; 25: 1211-1216. https://doi.org/10.3892/ or.2011.1194

[69] THUWAJIT C, THUWAJIT P, JAMJANTRA P, PAIROJKUL C, WONGKHAM S et al. Clustering of patients with intrahepatic cholangiocarcinoma based on serum periostin may be predictive of prognosis. Oncol Lett 2017; 14: 623-634. https://doi.org/10.3892/ol.2017.6250

[70] ENGELMANN JC, AMANN T, OTT-RÖTZER B, NÜTZEL $\mathrm{M}$, REINDERS $\mathrm{Y}$ et al. Causal modeling of cancer-stromal communication identifies PAPPA as a novel stroma-secreted factor activating $\mathrm{NFKB}$ signaling in hepatocellular carcinoma. PLoS Comput Biol 2015; 11: e1004293. https://doi. org/10.1371/journal.pcbi.1004293

[71] BLANCO FF, JIMBO M, WULFKUHLE J, GALLAGHER I, DENG J et al. The mRNA-binding protein HuR promotes hypoxia-induced chemoresistance through posttranscriptional regulation of the proto-oncogene PIM1 in pancreatic cancer cells. Oncogene 2016; 35: 2529-2541. https://doi. org/10.1038/onc.2015.325

[72] CHEN G, NAKAMURA I, DHANASEKARAN R, IGUCHI E, TOLOSA EJ et al. Transcriptional induction of periostin by a sulfatase 2-TGF $\beta 1$-SMAD signaling axis mediates tumor angiogenesis in hepatocellular carcinoma. Cancer Res 2017; 77: 632-645. https://doi.org/10.1158/0008-5472.CAN$15-2556$

[73] PLUGLisi F, PUPPIN C, PEGOLO E, ANDREETTA C, PASCOLETTI G et al. Expression of periostin in human breast cancer. J Clin Pathol 2008; 61: 494-498. https://doi. org/10.1136/jcp.2007.052506
[74] KIM GE, LEE JS, PARK MH, YOON JH. Epithelial periostin expression is correlated with poor survival in patients with invasive breast carcinoma. PLoS One 2017; 12: e0187635. https://doi.org/10.1371/journal.pone.0187635

[75] FARLING KB. Bladder cancer: Risk factors, diagnosis, and management. Nurse Pract 2017; 42: 26-33. https://doi. org/10.1097/01.NPR.0000512251.61454.5c

[76] KIM CJ, YOSHIOKA N, TAMBE Y, KUSHIMA R, OKADA $\mathrm{Y}$ et al. Periostin is down-regulated in high grade human bladder cancers and suppresses in vitro cell invasiveness and in vivo metastasis of cancer cells. Int J Cancer 2005;117: 51-58. https://doi.org/10.1002/ijc. 21120

[77] SILVERS CR, LIU YR, WU CH, MIYAMOTO H, MESSING $\mathrm{EM}$ et al. Identification of extracellular vesicle-borne periostin as a feature of muscle-invasive bladder cancer. Oncotarget 2016; 7: 23335-23345. https://doi.org/10.18632/oncotarget.8024

[78] KIM CJ, TAMBE Y, MUKAISHO KI, SUGIHARA H, KAGEYAMA $S$ et al. Periostin suppresses in vivo invasiveness via PDK1/Akt/mTOR signaling pathway in a mouse orthotopic model of bladder cancer. Oncol Lett 2017; 13: 4276-4284. https://doi.org/10.3892/ol.2017.6004

[79] LEE YJ, KIM IS, PARK SA, KIM Y, LEE JE et al. Periostinbinding DNA aptamer inhibits breast cancer growth and metastasis. Mol Ther 2013; 21: 1004-1013. https://doi. org/10.1038/mt.2013.30

[80] KYUTOKU M, TANIYAMA Y, KATSURAGI N, SHIMIZU $\mathrm{H}, \mathrm{KUNUGIZA} \mathrm{Y}$ et al. Role of periostin in cancer progression and metastasis: inhibition of breast cancer progression and metastasis by anti-periostin antibody in a murine model. Int J Mol Med 2011; 28: 181-186. https://doi.org/10.3892/ ijmm.2011.712

[81] ZHU M, SAXTON RE, RAMOS L, CHANG DD, KARLAN BY et al. Neutralizing monoclonal antibody to periostin inhibits ovarian tumor growth and metastasis. Mol Cancer Ther 2011; 10: 1500-1508. https://doi.org/10.1158/15357163.MCT-11-0046

[82] MORRA L, MOCH H. Periostin expression and epithelialmesenchymal transition in cancer: a review and an update. Virchows Arch 2011; 459: 465-475. https://doi.org/10.1007/ s00428-011-1151-5 